illustrating the difficulty of complete and accurate data collection. ${ }^{2}$

If national publication of institutional wound infection rates is a real possibility a standardised method of audit will clearly be necessary. We have shown that many wound complications after hernia surgery are not recorded in the hospital records and thus will not be audited by case note review. Many complications become apparent after discharge from hospital, are treated in the community, and have resolved by six weeks after operation. How can these problems best be detected?

A hospital based community surveillance team would be expensive to run and may not be necessary. Review of these patients in outpatient departments 10-14 days after operation with specific attention to recording visible and reported complications would have detected some $95 \%$ of the complications. However, it seems that many fundholding general practitioners will negotiate this sort of minor surgery without hospital follow up. Although general practitioners could provide the requisite audit information, we found a high incidence of general practitioners treating hernia wounds with antibiotics when there was little evidence of infection. Clearly, before we advocate publication of audit data, with all its implications, we must investigate more intensively the different methods of data collection.

Previous study of wound infections after hernia surgery report infection rates from $7 \cdot 3 \%$ (reported by the Public Health Laboratory Service at a time when many patients spent $10-14$ days in hospital) 5 to $1 \cdot 3 \%$ (reported in the United States). ${ }^{6}$ The low wound infection rate in the American study is likely to be a reflection of the definition of wound infection, which included wound breakdown but excluded lesser degrees of purulent discharge particularly associated with sutures or minor segments of the wound. We would, however, do well to emulate the results of this study.

In conclusion, this study has shown a high wound complication rate after hernia surgery. The community surveillance programme increased the detection of these complications fourfold. If we are going to audit our results seriously it is clear that new follow up practices are needed for short stay surgery. The optimal method of achieving this will need to be investigated in future research. The method of collection of audit data and the definition of complications must be established at a national level before decisions to publish comparative audit data are made.

We thank our surgical and general practitioner colleagues for their help and advice, in particular Professor Irving Taylor, Mr Gavin Royle, and Mr Colin Johnson, and also Mr Roger Farrow for his support.

1 Secretaries of State for Health, Wales, Northern Ireland, and Scotland. Working for patients. London: HMSO, 1989.

2 Buck N, Devlin HB, Lunn JN. The report of a confidential enquiry into perioperative deaths. London: Nuffield Provincial Hospital Trust and the perioperative deaths.

3 Anderson ID, Woodford M, de Dombal FT, Irving M. Retrospective study of 1000 deaths from injury in England and Wales. BMf 1988;296:1305-8.

4 Cruse P. Surgical infection surveillance. In: Karran SJ, ed. Controversies in surgical sepsis. New York: Praeger, 1980:327-32.

5 Public Health Laboratory Service. Incidence of surgical wound infection in England and Wales. Lancet 1960;ii:659-63.

6 Postoperative wound infections. The influence of ultraviolet irradiation of the operating room and of various other factors. Ann Surg 1964;160 (suppl): $1-192$

(Accepted 3 December 1991)

\title{
Motor neurone disease: a hospice perspective
}

\author{
Tony O’Brien, Moira Kelly, Cicely Saunders
}

\begin{abstract}
Objective-To describe and evaluate the management of patients with motor neurone disease from the perspective of a hospice.
\end{abstract}

Design-Retrospective analysis of hospice medical and nursing notes.

Setting-Established 62 bed teaching and research hospice.

Subjects-124 patients with motor neurone disease cared for by the hospice between January 1980 and November 1990.

Main outcome measures-Patient profile; functional status; symptom control and use of opioids; insight; mode and management of death.

Results -124 patients (67 women, 57 men) had a mean age 63.9 years. The median length of admission was 61.5 days (range 1 to 2147). 84 patients $(68 \%)$ were aware of their diagnosis and its implications when first seen by a hospice doctor. Functionally, the patients were very dependent. Symptoms such as pain, dyspnoea, and insomnia were major problems that responded well to opioids. Many patients were noted to deteriorate "suddenly," and in $58 \%$ of cases death occurred within 24 hours of this deterioration. When dying, 106 patients (94\%) were peaceful and settled. 101 patients $(89 \%)$ received opioids during this dying period. No patient choked to death.

Conclusions-Although motor neurone disease is an uncommon disorder, many of its symptoms occur commonly in medical practice and must be actively treated. Opioids are both safe and effective for such treatment. The term choking is both inaccurate and inappropriate in describing the cause of death in motor neurone disease and its use should be abandoned.

\section{Introduction}

Motor neurone disease is a progressive disorder of unknown aetiology for which there is no cure. This sometimes equates with the belief that there is "nothing more to be done." This feeling of hopelessness and despair is frequently sensed by patients and families.

In hospice practice, the family is the unit of care and particular attention is paid to the prompt and effective relief of distressing symptoms in conjunction with an appropriate level of psychosocial and spiritual support. There is opportunity to explore the nature of the illness and to address specific fears and anxieties, which are an inevitable concomitant of any progressive, invariably fatal disease. The pace of such discussions is strictly dictated by the patient and family. Death is not always neat and tidy, but a peaceful death is more likely to be achieved when the patient has received an optimal level of physical and emotional care throughout the illness. Hospice is a concept of care that can be applied in any setting.

\section{Methods}

Application for admission to the hospice was considered at the request of the patient's general practi- 
TABLE I-Age of patients with motor neurone disease on admission to hospice

\begin{tabular}{cc}
\hline Age (years) & $\begin{array}{c}\text { No (\%) of } \\
\text { patients } \\
(\mathrm{n}=124)\end{array}$ \\
\hline$<40$ & $4(3)$ \\
$40-$ & $8(7)$ \\
$50-$ & $26(21)$ \\
$60-$ & $45(36)$ \\
$70-$ & $37(30)$ \\
$\geqslant 80$ & $4(3)$ \\
\hline
\end{tabular}

TABLE II-Age at onset of symptoms related to survival time

\begin{tabular}{ccc}
\hline $\begin{array}{l}\text { Age at } \\
\text { onset }\end{array}$ & $\begin{array}{c}\text { No of } \\
\text { patients } \\
(\mathbf{n}=121)^{\star}\end{array}$ & $\begin{array}{c}\text { Mean (SE) } \\
\text { survival } \\
(\text { months) }\end{array}$ \\
\hline$<40$ & 3 & $77(11 \cdot 32)$ \\
$40-$ & 15 & $77(19 \cdot 04)$ \\
$50-$ & 30 & $48(9 \cdot 52)$ \\
$60-$ & 43 & $35(3 \cdot 29)$ \\
$70-$ & 27 & $28(4 \cdot 10)$ \\
$\geqslant 80$ & 3 & $13(5 \cdot 51)$ \\
\hline Total & 121 & $42(3 \cdot 90)$
\end{tabular}

$\star$ Date of death unknown for three patients.

TABLE III - Functional status of patients on admission to hospice. Figures are numbers

(percentages) of patients

\begin{tabular}{lc}
$\begin{array}{l}\text { Mobility: } \\
\text { Walks unaided } \\
\text { Walks with frame, stick, }\end{array}$ & $12(10)$ \\
$\quad$ or tripod & $16(13)$ \\
Walks with help from & \\
1-2 people & $27(22)$ \\
$\begin{array}{l}\text { Transfers with } \\
\text { supervision }\end{array}$ & $18(15)$ \\
Bedbound or chairbound & $51(41)$ \\
Meals: & \\
Feeds unaided & $24(19)$ \\
Feeds unaided if food & \\
specially prepared & $30(24)$ \\
Needs help or & \\
supervision & $24(19)$ \\
Must be fed & $46(37)$ \\
Diet: & $26(21)$ \\
All foods & $52(42)$ \\
Semisolids & \\
Liquidised or pureed & $33(27)$ \\
food & $3(2)$ \\
Liquids only & $10(8)$ \\
Fed through tube & \\
Speech: & $25(20)$ \\
Normal & $54(44)$ \\
Slurred but intelligible & 5 \\
Slurred but unintelligible & $14(11)$ \\
Groans & $7(6)$ \\
No speech & $24(19)$ \\
\hline
\end{tabular}

TABLE IV-Symptoms of patients on admission to hospice. Figures are numbers (percentages)

\begin{tabular}{|c|c|}
\hline & $\begin{array}{l}\text { Patients } \\
\text { with } \\
\text { motor } \\
\text { neurone All } \\
\text { disease patients } \\
(n=124)(n=809)\end{array}$ \\
\hline \begin{tabular}{l} 
Constipation \\
Pain \\
Cough \\
Insomnia \\
Dyspnoea \\
Dribbling saliva \\
Urinary \\
\multicolumn{1}{c}{ incontinence }
\end{tabular} & $\begin{array}{ll}81(65) & 388(48) \\
71(57) & 558(69) \\
66(53) & 380(47) \\
59(48) & 235(29) \\
58(47) & 405(50) \\
47(38) & \\
18(15)\end{array}$ \\
\hline
\end{tabular}

tioner or hospital consultant. In all cases, the diagnosis was established before admission to the hospice. Typically, the diagnosis of motor neurone disease was made by a neurologist and based on clinical findings in conjunction with electrophysiological studies.

A systematic review of the medical and nursing case notes was undertaken by a research nurse (MK) under the supervision of a medical consultant (TO'B). Standardised notes were in use for the duration of the review period; in addition to a checklist of symptoms they included demographic data, history of the current illness, drug history, social and bereavement aspects, insight of patient and family, spiritual aspects, and the aims and expectations of each patient. Data thus retrieved were entered on to a computer database for storage and analysis.

\section{Results}

PATIENTS

There were 124 patients ( 67 women, 57 men) with a mean age of 63.9 years (SE 0.95 ) (table I). The median time spent under the care of the hospice was 61.5 days and the mean number of admissions was $1.37(0 \cdot 12)$. The mean duration from the onset of symptoms to diagnosis was $13.53(1.36)$ months; the mean survival (from onset of symptoms to death) was $42(3.90)$ months; $82 \%$ of patients (102) died within five years, $13 \%$ (16) died within 5-10 years, $4 \%$ (5) died within 10-20 years, and one patient lived for 22 years. Table II shows the relation between age at onset of illness and survival time. Age at onset of illness was correlated with survival, giving a Pearson's product moment correlation coefficient of $-0.37(p=0.01)$

At the time of referral 91 patients $(73 \%$ ) were being cared for at home, a further $31(25 \%)$ were in hospital, and two $(2 \%)$ were in nursing homes. The main care was a spouse in 77 cases $(62 \%)$ and a son or daughter in 26 cases $(21 \%)$. The principal reasons given for hospice referral were nursing care $(70(56 \%)$ patients), respite care $(25(20 \%))$, symptom control $(19(15 \%))$, and terminal care $(10(8 \%))$

\section{FUNCTIONAL STATUS}

The degree of functional impairment was assessed by focusing on four main areas: mobility (providing an index of lower limb function); meals or feeding (upper limb function); diet (swallowing difficulties); speech (communication difficulties). Table III shows the degree of impairment when patients were admitted to the hospice.

\section{SYMPTOMS}

Table IV outlines other symptoms present when patients were first reviewed by a hospice doctor and compares the prevalence of these symptoms in patients with motor neurone disease and in all patients admitted to the hospice. The low priority given to symptom control is evident from the fact that only $15 \%$ of patients were referred for symptom control.

\section{OPIOIDS}

At the time of referral, only 15 patients $(12 \%)$ were receiving an opioid even though 71 patients $(57 \%)$ had uncontrolled pain. While under the care of the hospice, 109 patients $(88 \%)$ received an opioid on at least one occasion. The mean dose used was $30(2 \cdot 34) \mathrm{mg} / 24 \mathrm{~h}$ (oral morphine equivalent), and the mean duration of treatment was $58(18.51)$ days. One patient was maintained on a stable dose of morphine for over five years. The response to opioids in motor neurone disease is summarised in table $\mathrm{V}$.

\section{INSIGHT}

At the time of first contact with the hospice, 84 patients (68\%) were fully aware of both the nature of motor neurone disease and its likely progression. A higher proportion of main carers $(102 ; 82 \%)$ were fully informed. A further 31 patients $(25 \%)$ were aware of their diagnosis without fully appreciating that this was a progressive and ultimately fatal disorder. Sixty eight patients (55\%) had a calm acceptance of their situation $46(37 \%)$ were anxious. The principal fears expressed were of increasing dependency and choking. Nine patients $(7 \%)$ were clinically depressed.

On first review, 55 patients (44\%) were hoping for better symptom control, a further 52 patients $(42 \%)$ wanted a temporary halt in the progression of their weakness, and eight patients (6\%) expressed the wish that death would come quickly. Ten patients $(8 \%)$ were hoping for a "cure."

DEATH

The major cause of death in motor neurone disease is respiratory failure. ${ }^{12}$ In this series, 113 patients died in the hospice. Of these, $45(40 \%)$ deteriorated suddenly and died within 12 hours; 20 (18\%) died within 24 hours; $27(24 \%)$ within three days, and $19(17 \%)$ within seven days. Two patients (2\%) lived for more than a week after sudden deterioration. The clinical picture was one of acute or acute on chronic respiratory failure. One hundred and six patients (94\%) were settled during this dying phase. During this period $101(89 \%)$ patients received opioids (mean (SE) four hourly dose $4(0.31) \mathrm{mg}$, parenteral diamorphine equivalent), $72(64 \%)$ received phenothiazines, $75(66 \%)$ received anticholinergics, and $68(60 \%)$ received benzodiazepines.

There was a clinical suspicion that one patient had died after a choking episode. At postmortem examination, however, the airways were completely clear and the cause of death was shown to be a recent massive myocardial infarction. In no other instance was there even suspicion of any patient choking to death. Nineteen patients had a postmortem examination and in each case the airways were entirely free of foręign matter (J Martin, personal communication).

\section{Discussion}

Motor neurone disease occurs more commonly in men $(1 \cdot 6: 1)^{3}$ and predominantly affects the $60-80$ year age group. ${ }^{4}$ So consistent is the age distribution that Kondo has noted that age remains the strongest determinant of risk. ${ }^{5}$ The mean time from the onset of symptoms to diagnosis was 13.5 months, which is less than that reported by Newrick and Langton-Hewer. ${ }^{6}$ This discrepancy reflects methodological difficulties in obtaining such data retrospectively.

Data on survival times in motor neurone disease show considerable variation. Schiffer et al reported a median survival of 24 months, but with five year and 10 year survival rates of $33 \cdot 1 \%$ and $31 \cdot 1 \%$ respectively. ${ }^{8}$ In our series $18 \%$ of patients survived for more than five years, which compares with a $20 \%$ five year survival reported by Mulder and Howard. ${ }^{9}$ Rowland noted that life expectancy generally is shorter for patients whose symptoms start after age $60 .^{10}$

\section{FUNCTIONAL STATUS}

Our patients needed considerable support to meet

TABLE $\mathrm{v}-$ Response of patients with motor neurone disease to opioids. Figures are numbers (percentages)

\begin{tabular}{lllcl}
\hline & Good & Fair & No response $\begin{array}{r}\text { Assessment } \\
\text { not possible }\end{array}$ \\
\hline Dyspnoea $(n=59)$ & $48(81)$ & $2(3)$ & $3(5)$ & $6(10)$ \\
Pain $(n=49)$ & $36(74)$ & $9(18)$ & 0 & $4(8)$ \\
Insomnia $(n=22)$ & $18(82)$ & $3(14)$ & $1(5)$ & 0 \\
\hline
\end{tabular}


their basic physical needs. It is remarkable that at the time of referral 91 patients $(73 \%)$ were being cared for in their own homes. This stands as a tribute to the courage and resilience of so many patients with motor neurone disease and also to the dedication and resourcefulness of their families and friends.

\section{PAIN AND SYMPTOM CONTROL}

The management of symptoms in motor neurone disease demands strict attention to detail. For every patient each symptom must be assessed and appropriate treatment started. Common symptoms such as pain, constipation, dyspnoea, and insomnia must be actively treated from the outset. Bulbar symptoms present particular difficulties and are best managed within the framework of a multidisciplinary team. Hillel and Miller give a detailed account of the management of bulbar symptoms in motor neurone disease. ${ }^{.1}$

Pain is a common and troublesome problem in motor neurone disease. ${ }^{12-14}$ Newrick and LangtonHewer noted that pain was a major symptom in $64 \%$ of patients and was described as aching, cramping, burning, shock-like, or indescribable. ${ }^{12}$ Pain may be felt at single or multiple sites and is frequently worse at night. The precise aetiology of the pain is unknown but joint stiffness, muscle cramp, and skin pressure may all contribute. ${ }^{13}$

\section{OPIOIDS}

Hospices have shown the efficacy and safety of opioids in advanced cancer. The value of opioids in motor neurone disease is generally accepted but their use is often reserved for the "terminal" phase. ${ }^{13-15}$ The introduction of opioids must be strictly dictated by the nature and severity of symptoms and not based on any crude assessment of the likely prognosis. Morphine is the oral opioid of choice ${ }^{16}$ and may be given as an elixir four hourly or 12 hourly as a slow release preparation. The starting dose should be low and then titrated against the clinical response. An antiemetic may be required initially and laxatives should be routinely prescribed. Oliver gives a comprehensive account of symptom management in motor neurone disease. ${ }^{1 ?}$

\section{INSIGHT}

Many patients, and an even higher proportion of families were well informed regarding the nature of the illness. Not infrequently, patients have anxieties based on inaccurate and misleading information, usually concerning the mode of death. In general, however patients were very accepting of their situation and had entirely reasonable expectations of their carers. The low incidence of depression (7\%) corresponds closely with that reported by Newrick and Langton-Hewer.

DEATH

The most typical clinical picture preceding death is one of a sudden and rapid deterioration, ${ }^{18}$ due to respiratory failure. ${ }^{19}$ This sudden deterioration in respiratory function is often inaccurately described as "choking." Choking has been defined as "a sudden inability to breathe due to acute obstruction of the pharynx, larynx, or trachea. ${ }^{20}$ No patient in this series choked to death. The term choking is an emotionally charged one and does not accurately describe the cause of death in motor neurone disease. Its use must be abandoned.

Motor neurone disease is a progressive disorder characterised by increasing weakness of muscle. The muscles of respiration are not spared in this process and ultimately a point is reached when life can no longer be sustained. This occurs as part of the course of the disorder and will occur independently of any changes in medication. Opioids are of particular value in relieving the acute distress associated with such a collapse in ventilatory function. In our experience, the judicious use of opioids at any stage of the disease offers excellent palliation of symptoms without affecting either the course or the duration of the illness.

In caring for patients with motor neurone disease, the overall impression is not one of disability and loss but rather of the immense potential of each individual for growth and creativity in the face of progressive physical deterioration. All professional carers must work in a constructive and coordinated fashion to enable patients to live to their maximum potential

We thank the members of the St Christopher's Hospice Research Committee for their invaluable guidance and support; our colleagues and the patients and families at $\mathrm{St}$ Christopher's, who have taught us so much; and the Motor Neurone Disease Association for their generous financial support.

1 Howard RS, Wiles CM, Loh L. Respiratory complications and their management in motor neuron disease. Brain 1989:112:1155-70.

Smith RA, Dawson A, Foroozan P. Pharmacologic and surgical modalities. In. Mulder DW, ed. The diagnosis and treatment of amyotrophic lateral sclerosis. Boston: Houghton Mifflin, 1980;241-67.

3 Mulder DW, Kurland LT, Motor neuron disease: epidemiologic studies. Adv Exp Med Biol 1987;209:325-32.

4 Cochrane GM, ed. The management of motor neurone disease. Edinburgh: Churchill Livingstone, 1987.

5 Kondo K. Epidemiology of motor neurone disease: ageing and exhaustion hypotheses revisited. In: Rose FC, ed. Research progress in motor neurone disease. London: Pitman, 1984:20-33.

6 Newrick PG, Langton-Hewer R. Motor neurone disease: can we do better? A study of 42 patients. BMf1984;289:539-42.

7 Norris FH, Denys EH, Sang KU, Mukai E. The natural history of ALS in a specified population, with comments on risk factors, prognosis and symptomatic treatments. Rinsho Shinkeigaku 1989;29:1485-92.

8 Schiffer D, Brignolio F, Chio A, Leone M, Rosso MG. A study of prognostic factors in motor neuron disease. Adv Exp Med Biol 1987;209:255-63.

9 Mulder DW, Howard FM. Patient resistance and prognosis in amyotrophic lateral sclerosis. Mayo Clin Proc 1976;51:537-41.

10 Rowland LP. Motor neuron diseases: the clinical syndromes. In: Mulder DW, ed. The diagnosis and treatment of amyotrophic lateral sclerosis. Boston: Houghton Mifflin, 1980:7-33.

11 Hillel AD, Miller RM. Management of bulbar symptoms in amyotrophic lateral sclerosis. Adv Exp Med Biol 1987;209:201-21.

12 Newrick PG, Langon-Hewer R. Pain in motor neuron disease. 7 Neurol Neurosurg Psychiatry 1985;48:838-40.

13 Rose FC. The management of motor neuron disease. Adv Exp Med Biol 1987;209:167-74

14 Rosin AJ. The problems of motor neurone disease. Age Ageing 1976;5:37-42.

15 Norris FH, Smith RA, Denys EH. Motor neurone disease: towards better care. $B M \mathcal{F} 1985 ; 291: 259-62$.

16 World Health Organisation. Cancer pain relief. Geneva: WHO, 1986.

17 Oliver D. Motor neurone disease. Exeter: Royal College of General Practitioners, 1989.

18 Saunders C, Walsh TD, Smith $M$. Hospice care in motor neuron disease. In Saunders C, Summers DH, Teller N, eds. Hospice: the living idea. London: Edward Arnold, 1981:126-47.

19 Gawel MJ, Somerville J, Beggs C. Motor neurone disease: the aggressive approach. Clinical Rehabilitation 1989;3:309-12.

20 Churchills.Medical Dictionary. New York: Churchill Livingstone, 1989.

(Accepted 3 December 1991) 